\title{
Suppression of perceptual organization in the auditory mode by the presence of visual stimuli
}

\author{
JAMES 0. SPENCER* \\ California State University, Northridge, Calif. 91324
}

Differences in perceptual organization of vocal nonsense, in the presence of visual displays of varying complexity, were studied in 48 college students. Freedom to respond to nonsense appeared to be inversely related to the degree of visual complexity. A theoretical framework is suggested to explain the differences and to relate the results to elicited aggression experiments.

\section{INTRODUCTION}

Considerable effort has been devoted to experiments where the $\mathrm{E}$ attempts to influence the perception of the $S$ by manipulating variables not explicitly related to the stimulus. Prior information has been used effectively to retard as well as to enhance recognition performance (Zangwill, 1937; Steinfeld, 1967). Hunger has been shown to increase food-related responding to ambiguous stimuli (Levine, 1942), while thirst has apparently affected the perception of size (Klein, 1957). The relative value of a stimulus object can affect the perception of its size and the variability of response to it (Bruner \& Postman, 1948; Dukes \& Bevan, 1952; Jenkins, 1957). A somewhat more sensational result has been obtained in the elicited aggression experiments in which an increase in the number of aggressive responses is obtained in the presence of weapons, fight scenes, or other stimuli associated with violence (Berkowitz \& Le Page, 1967; Berkowitz, 1970).

The present experiment questioned whether stimulus-related responses could be obtained from other more cognitively oriented stimulus items in a fashion similar to the aggression experiments and whether complexity of visual information alone would be sufficient to affect the response rate to stimuli in the auditory mode. Such an effect of complexity on perception would appear to be confounded with stimulus-related responding. For example, if a change in response strength could be expected from any manipulation of the perceptual field, this variable might need to be considered in elicited behavior experiments. Further, a method for quantification of cross-modality influences on perception could emerge.

In order to explore the differences that could arise in auditory perception as a result of manipulating the complexity of the visual field, the number of words organized out of nonsense in the presence of various

*Now at Claremont Graduate School, Claremont, California 91711. I offer my eternal gratitude to Roger Moss for serving relentlessly as an example of existential piety. $O$. Thomas Law is the sponsor of this article and takes full editorial responsibility. visual arrays was compared. The notion that an increase in the complexity of the visual array would tend to constrict response avenues and produce a general decrement in responsiveness to ambiguous stimuli was suggested by preliminary experiments in this laboratory.

\section{PROCEDURES}

The Ss were 48 undergraduate students enrolled in introductory psychology courses. An ambiguous nonsense test stimulus was produced by playing a tape of male speech in reverse over monaural headphones for $3 \mathrm{~min}$. A mean loudness of $32 \mathrm{~dB}$ was maintained to obscure the nature of the stimulus. Loudness was recalibrated for each $S$. The Ss were placed in a stark room, furnished only with the table at which they were seated, experimental headphones and recorder, a pencil with several sheets of unlined paper, and the appropriate visual stimulus for the group. Ss were instructed to attend to the conversation on the headphones and to transcribe the distinguishable words on the paper provided. The Ss were assigned to three groups of 15,17 , and $16(\mathrm{~A}, \mathrm{~B}, \mathrm{C})$ each. ${ }^{1}$ The first two groups were tested in the presence of either 15 or an average of 9 items, respectively, while the third, without an array, acted as control. Items were chosen for each $\mathrm{S}$ from a list of 20 , consisting of tools, books, utensils, and other items common to the household.

\section{RESULTS}

The mean number of words transcribed by each group is graphed in Fig. 1. The means were 11, 6.71, and 4.79

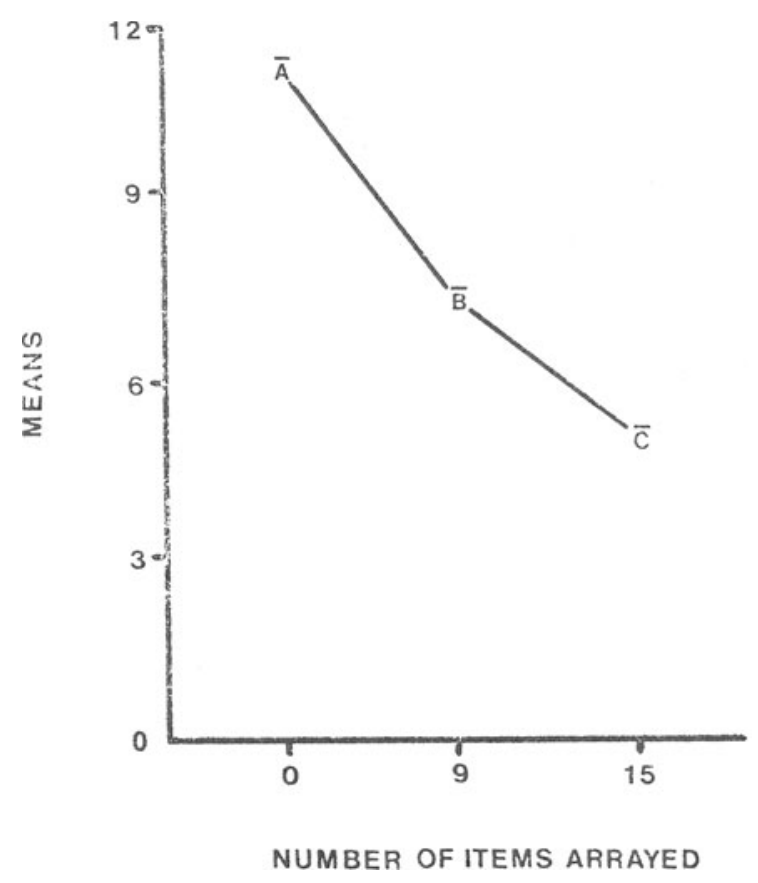

Fig. 1. Group means. 


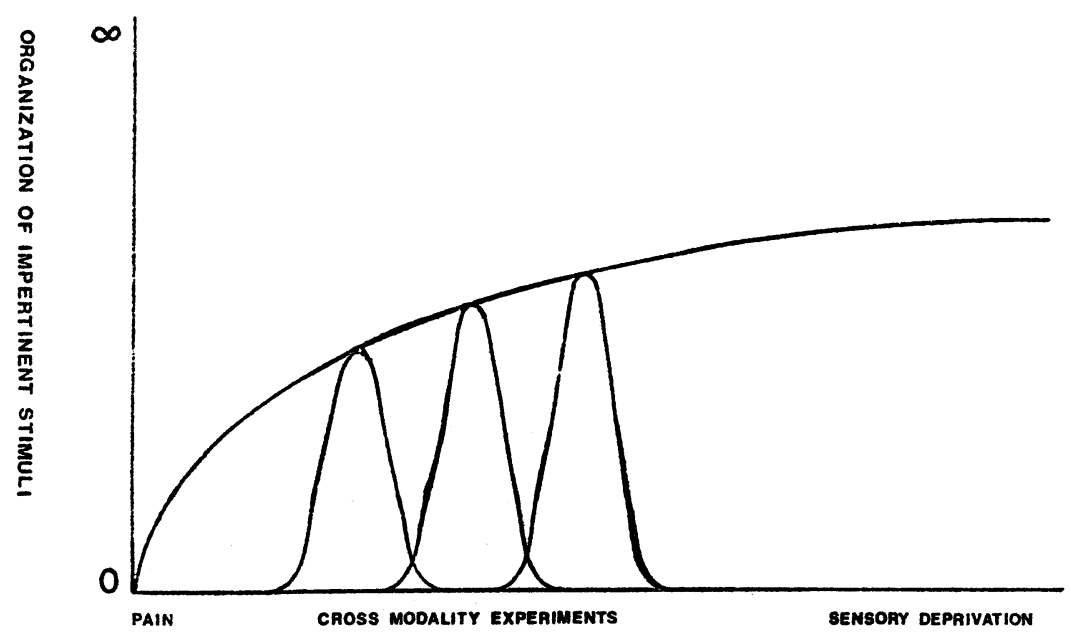

Fig. 2. Proposed perceptual organization continuum.

STIMULUS CONFIGURATION

for Groups A, B, and C. A Kruskal-Wallis analysis of variance by ranks yielded $\mathrm{H}=129.45, \mathrm{df}=2, \mathrm{p}<.001$. Subsequent Mann-Whitney U-tests of between-group differences yielded Us of $67 \quad\left(\mathrm{~N}_{1}=12, \mathrm{~N}_{2}=14\right)$, $\mathrm{p}<.001$, and $80\left(\mathrm{~N}_{1}=14, \mathrm{~N}_{2}=14\right), \mathrm{p}<.001$, for the $\mathrm{A}-\mathrm{B}$ and $\mathrm{B}-\mathrm{C}$ comparisons. The trend of the means reflects the direction of prediction.

\section{DISCUSSION}

The experiment described here is evidence for a measurable cross-modality influence of irrelevant information on perception. The theoretical framework suggested draws upon the obvious as well as sophisticated experimentation for its foundation. It is proposed that the phenomenon under study is a brief portion of a continuum that can be identified in the presence of pain as well as in the absence of stimuli. The most naive observer is cognizant of an organism's inability to respond meaningfully to impertinent stimuli in the presence of pain. For this model, such a suppression of responses is conceived of as one end of the continuum, while at the other, the hallucinatory effects of sensory deprivation (Solomon, 1957) offer a convenient antithesis. As conditions are made to proceed from pain through successive reductions in the paratarget stimulus configuration, a whole family of curves might be expected to emerge relative to a single sensory mode (see Fig. 2). As the paratarget stimulus decreases to zero, the individual is increasingly free to organize the target stimulus in perception toward more productive ends. In the case of the present experiments, as the visual field put fewer demands for organization on the Ss, they became more apt to respond to the target stimulus in an organized fashion. Were this couched in hypothesis testing terms, it would be easy to suppose that the hallucinatory reports of sensory-deprived individuals are a desperate attempt to discover the meaningful alternative that fits their sensory world. The individual in pain, on the other hand, is quite aware of what the important information is in his experience that requires attention. Elicited behavior by introduction of behavior-related stimulus items would seem to suggest two nonexclusive interpretations under this model. The first and most obvious is that the presence of the specific items suppressed all but those responses associated with the stimuli. A second argument relies on the general austerity of the controlled experimental setting to suggest that possibly the paucity of complex stimuli in the perceptual field results in a poorly differentiated increase in overall responding.

\section{REFERENCES}

Berkowitz, L. The contagion of violence. In W. J. Arnold and $M$. M. Page (Eds.), Nebraska symposium on motivation. Lincoln, Nebr: University of Nebraska Press, 1970.

Berkowitz, L., \& Le Page, A. Weapons as aggression-eliciting stimuli. Journal of Personality \& Social Psychology, 1967, 7, 202-207.

Bruner, J. S., \& Postman, L. J. Symbolic value as an organizing factor in perception. Journal of Social Psychology, 1948, 27, 203-208.

Dukes, W., \& Bevan, W. Accentuation and response variability in the perception of personally relevant objects. Journal of Personality, 1952, 20, 457-465.

Jenkins, N. Affective processes in perception. Psychological Bulletin, 1957, 54, 100-127.

Klein, G. S. Need and regulation. In M. R. Jones (Ed.), Nebraska symposium on motivation. Lincoln, Nebr: University of Nebraska Press, 1957. Pp. 224-274.

Levine, R., Chein, I., \& Murphy, G. The relation of the intensity of a need to the amount of perceptual distortion: A preliminary report. Journal of Psychology, 1942, 13, 283-293.

Solomon, P. Sensory deprivation: A review. American Journal of Psychiatry, 1957, 114, 357-363.

Steinfeld, G. J. Concepts of set and availability and their relation to the reorganization of ambiguous stimuli. Psychological Review, 1967, 74, 505-522.

Zangwill, $O$. L. A study of the significance of attitude in recognition. British Journal of Psychology, 1937, 28, 12-17.

\section{NOTE}

1. Eight $S s$ were discarded from the analysis because of their sophistication. These Ss identified the stimulus immediately upon entering the experimental setting. It was assumed that omission on this basis would not favor any group. A chi-square test of this assumption yielded $\chi^{2}=1.903$, df $=2,50, p<.30$. The resulting group Ns are 12, 14, and 14 .

(Received for publication October 19, 1972.) 